Relations industrielles

Industrial Relations

\title{
Principes d'économie politique, par Roger Dehem, Dunod, Paris
} 1962, pp. 189.

\section{Jacques St-Laurent}

Volume 17, numéro 4, octobre 1962

URI : https://id.erudit.org/iderudit/1021493ar

DOI : https://doi.org/10.7202/1021493ar

Aller au sommaire du numéro

\section{Éditeur(s)}

Département des relations industrielles de l’Université Laval

\section{ISSN}

0034-379X (imprimé)

1703-8138 (numérique)

Découvrir la revue

Citer ce compte rendu

St-Laurent, J. (1962). Compte rendu de [Principes d'économie politique, par Roger Dehem, Dunod, Paris 1962, pp. 189.] Relations industrielles / Industrial Relations, 17(4), 507-507. https://doi.org/10.7202/1021493ar

Tous droits réservés @ Département des relations industrielles de l’Université Laval, 1963
Ce document est protégé par la loi sur le droit d'auteur. L’utilisation des services d'Érudit (y compris la reproduction) est assujettie à sa politique d'utilisation que vous pouvez consulter en ligne.

https://apropos.erudit.org/fr/usagers/politique-dutilisation/ 
tions à remplir qui rappellent des refrains déjà connus. Et lon sait ce que cela veut dire.

Cinq ans d'expérience syndicale dans un pays en pleine transformation économique et sociale, c'est bien peu. Mais il est intéressant de voir comment à partir d'une conception de la liberté, comme nous l'entendons dans le monde occidental, le syndicalisme est en train de s'organiser avec la sympathie du gouvernement. Ce rapport est une contribution utile à l'étude du syndicalisme et des relations industrielles dans le monde.

\section{Gérard Dion}

\section{Principes déconomie politique, par Ro-} ger Dehem, Dunod, Paris 1962, pp. 189.

Ce n'est pas tous les jours qu'un professeur de l'Université Laval publie un livre sérieux sur l'économie. C'est un évènement rare qu'il vaut la peine de signaler.

Le livre du professeur Dehem s'adresse à ceux qui s'intéressent aux grands problèmes économiques de notre temps. Il ne s'adresse pas qu'à ceux dont l'étude des phénomènes économiques est l'occupation continuelle. Tous ceux que touchent les problèmes de l'élimination de la misère o ou \&l'élimination du bien-être de la société \$ et qui veulent en amorcer une étude sérieuse auront profit à lire les « Principes d'économie politique ».

Le livre, bien qu'il soit un livre d'initiation, bien que l'auteur, pour des raisons pédagogiques, se soit abstenu d'utiliser les techniques d'analyse habituelles aux économistes, ne va pas sans difficulté. L'Auteur a échappé à la tentation de rendre trop facile ce qui ne l'est pas en risquant de perdre l'essentiel. C'est pourquoi son livre est à la fois élémentaire et approfondi. Dans ce dernier sens, c'est un livre difficile. Mais la connaissance des phénomènes économiques et des règles qui les régissent l'est aussi.

N'importe lequel lecteur se sent en terrain connu, lorsque l'auteur réfère, par exemple, à cet anglais Child comme à «un précurseur typique des plaideurs de politique économique en fonction d'intérêts particuliers 》; ou lorsqu'il rappelle que les phénomènes économiques sont liés \& non seulement aux éléments atmosphériques, mais aussi à l'échelonnement d'événements sociaux telles les fêtes de Noël et de Pâques 》. Le même lecteur se sent cependant moins à l'aise lorsque l'auteur parlera sans explication supplémentaire de $<$ la violation des conditions d'un optimum parétien $\gg$, (p. 160) ou de la démonstration faite par certains auteurs du fait que * si l'épargne pouvait être tellement abondante que sa productivité marginale descende à zéro, la «productivité sociale» de l'économie serait maxima ». (p. 159).

Mais ces passages plus difficiles devraient être pour le lecteur une invitation à un approfondissement des concepts auxquels sont habitués les économistes, lesquels concepts sont nécessaires à la compréhension des phénomènes économiques.

Cet approfondissement est rendu facile par les excellentes références qui apparaissent à la fin de chaque chapitre et qui ont le mérite d'être sûres et de n'être pas trop nombreuses.

Signalons enfin que le style est correct et concis et que le vocabulaire est moderne ( guidage », 《retombées 》, « la nouvelle vague \$, « déviation conservatrice $\gg$ ).

Le livre de M. Dehem n'est pas un livre parfait. Mais c'est un livre honnête et sérieux. Il a le mérite de ne pas éloigner les non-initiés par une surcharge de preuves géométriques ou de relations mathématiques; d'apporter aux facteurs institutionnels et politiques plus d'importance qu'en accordent les économistes; de ne pas esquiver la complexité d'une analyse qui conduit à des solutions possibles mais pas toujours certaines; de rendre évident que les problèmes économiques ne peuvent pas être résolus en disant <hocus pocus $\gg$ ou par quelques gestes de magiciens.

Nous souhaitons, avec l'auteur, que ce livre conduise à d'autres.

\section{Jacques St-Laurent}

The Economics of Trade Unions, by Albert Rees, University of Chicago Press, 1962, pp. 202.

Voici le dernier venu de l'excellente collection « Cambridge Economic Hand- 